Research Article

\title{
The Dangerous Couple: Illegal Mining and Water Pollution-A Case Study in Fena River in the Ashanti Region of Ghana
}

\author{
Albert Ebo Duncan \\ Department of Water and Sanitation, School of Physical Sciences, College of Agriculture and Natural Sciences, \\ University of Cape Coast, Cape Coast, Ghana \\ Correspondence should be addressed to Albert Ebo Duncan; aduncan@ucc.edu.gh
}

Received 23 March 2020; Accepted 16 July 2020; Published 31 July 2020

Academic Editor: Rita Rosa Plá

Copyright $(92020$ Albert Ebo Duncan. This is an open access article distributed under the Creative Commons Attribution License, which permits unrestricted use, distribution, and reproduction in any medium, provided the original work is properly cited.

The threat posed by illegal mining to the quality of water resources in Ghana has become a major public concern due to the closing down of some water treatment plants in the country. This study aimed to investigate heavy metal pollution in Fena River due to the illegal mining activities. The study was based on 72 samples from six sampling points for a period of 12 months (Januar$\mathrm{y}$-December). Six heavy metals such as lead $(\mathrm{Pb})$, cadmium $(\mathrm{Cd})$, copper $(\mathrm{Cu})$, mercury $(\mathrm{Hg})$, iron $(\mathrm{Fe})$, and zinc $(\mathrm{Zn})$ in water were investigated from Fena River in the Amansie Central District in the Ashanti Region of Ghana. The ranges of the heavy metals in water were BDL-1.041, 0.01-0.703, BDL-0.24, 0.17-16.43, 0.46-1.02, and BDL for Pb, Cd, Cu, Fe, Zn, and Hg. Three metals exceeded the safe drinking water guidelines making water generally unsafe for drinking and domestic purposes. According to Nemerow's pollution index results, three metals, namely, $\mathrm{Cd}, \mathrm{Pb}$, and $\mathrm{Fe}$, were the principal metal pollutants in the study area, whereas $\mathrm{Hg}, \mathrm{Cu}$, and $\mathrm{Zn}$ were found not to contribute to the pollution effect. However, of the polluting metals, only Cd polluted all the six sampling sites, whereas $\mathrm{Pb}$ polluted five out of the six sampling sites. The most striking of the results is the absence of mercury in all the sites studied. The findings from the water quality index confirm that only two of the sites recorded marginal water quality, whereas the remaining four sites recorded poor water quality. The high levels of heavy metals polluting water and the deteriorating water quality are due to the illegal mining activities occurring within and around Fena River.

\section{Introduction}

Mining is the extraction (removal) of minerals and metals from the Earth, e.g., manganese, gold, copper, tin, etc. For decades, the extraction and subsequent processing of gold have provided thousands of indigenous people with employment and many continents with a wealth of economic development [1]. Notwithstanding this, there are also many environmental problems and challenges associated with mining which stem from the contamination of, as well as competition for, surface and groundwater [2]. Water contamination from mining activities results from the discharge of effluents, which contain toxic chemicals such as cyanide and other organic chemicals used in the processing of mineral ores. These chemicals together may result in effluent with high acid levels which can either seep into underground water or flow into the environment (surface water bodies) posing danger to the nearby community's especially those which depend on such water bodies for drinking and other domestic purposes. Another concern has to do with the leaching of heavy metal oxides (including lead and zinc oxides) which sometimes find their way into the environment and more specifically seep into surface and underground water bodies, posing danger to aquatic life as well as communities which depend on such resources [3].

Sometimes one is tempted to believe that the mineral endowment of most African countries is more of a curse than a blessing as the above mining problems are a case in point in most African countries where these minerals are extracted. Africa harbors the world's largest mineral reserves of platinum, gold, diamonds, chromite, manganese, and vanadium [4]. Unfortunately, Africa retains the environmental burden of mining, whose effects also reduce whatever it receives from the benefits of its minerals [5]. While the 
resource productivity in European Union countries is increasing, many mineral-rich countries in Africa are still struggling to cope with the environmental impacts of rising extraction rates: huge amounts of waste, wastewater, and dissipative losses. Legacy of mining in Africa is generally that of large unfilled holes and abandoned artisanal mining sites. One major challenge which has arisen in most African countries is the challenge of uncontrolled small-scale and illegal mining activities. Small-scale mining is currently seen globally as a source of a determinant for environmental degradation and resource depletion in areas where such precious minerals are mined [3]. The situation is even more alarming when the camera is shifted to illegal mining popularly known as "galamsey" in Ghana. More people are engaging in this illegal mining, that is, mining without any permit or license from the regulatory bodies such as the Minerals Commission of Ghana.

Classically, the country Ghana located in West Africa is equitably endowed with rich mineral resources, thus formerly called Gold Coast. It is the second-largest gold producer on the continent after South Africa. Mining (largescale and artisanal small-scale) accounts for about $9.1 \%$ of Ghana's gross domestic products (GDP) and serves as a source of employment for about 260,662 citizens in the formal sector [6]. According to Aryee et al. [3], an estimated 80,000 locals, including women, are currently involved in small-scale mining (legal and illegal) of gold in Ghana. It is therefore not surprising that Ghana also has the largest artisanal and small-scale mining in Africa $(1,100,000)$ with estimated dependents of 4,400,000 [2]. Small-scale miners in the past were described as "poor people," individuals or small groups who depend upon mining for a living, who use rudimentary tools and techniques (e.g., picks, chisels, sluices, and pans) to exploit mineral deposits. This definition does not hold any longer in Ghana and specifically in Fenaso where this research was conducted. In Fenaso, small-scale and illegal mining are controlled by the rich who employ the use of sophisticated equipment resulting in modifying the landscapes and potentially having a long-term impact on communities and the natural resources due to their physical degrading nature, as well as the use of chemicals and other harmful substances [5]. For the past thirty years, Fenaso town has seen increasingly rapid advances in illegal mining popularly known as "galamsey" with very sophisticated and complex equipment.

This has created many challenges in Fena River. The first challenge is the diversion of the river path and mining on the river bed resulting in a high level of siltation that threatens the drying up of the river. The second problem is the introduction of high levels of suspended solids that are potential carriers of heavy metals into the river. The high level of suspended solids has also resulted in the high cost of treatment in some water treatment plants and their eventual closure as well. The third problem is that the gravels, mud, and rocks displaced during river dredging for the mineral have disrupted the natural flow of the river. The fourth problem is that the fishermen in the area complain of not enjoying a good harvest as in the past. The sustainability of the river flow cannot be guaranteed but that is not the focus of this study. These challenges pose a serious threat to public health in Fenaso and its environs, especially for those who still depend on the river for domestic activities such as cooking during water stress conditions. However, the metal levels in the river have not been measured. The main aim of this investigation is to assess the pollution potential of some selected heavy metal levels and their threat to public health in the study area.

\section{Materials and Methods}

2.1. The Study Area and Sampling. The study was carried out in the Amansie Central District in the Ashanti region. The Amansie Central District is located in the southern part of the Ashanti Region with a total land area of about 710 square kilometers. It shares common boundaries with Amansie East to the northeast, Amansie West to the west, Obuasi $\mathrm{Mu}$ nicipal Assembly to the southeast, Adansi North to the east, Adansi South to the south, and Upper Denkyira to the south. The district can be found within latitude $6000^{\circ} \mathrm{N}$ and $6030^{\circ} \mathrm{N}$ and longitude $1000^{\circ} \mathrm{W}$ and $2000^{\circ} \mathrm{W}$. The district is located within the forest dissected plateau region with an average height between 150 meters and 300 meters above sea level. Topographically, the area is relatively flat with occasional undulating upland of 240 meters to 300 meters above sea level around Numereso, Apitisu, Tweapease, and Abuakwa. The district experiences bimodal rainfall distribution with the major season falling between March and July, whilst the minor season is between September and November. This is separated by short cool dry season in August and a relatively long dry season from November to March. However, the above weather condition is hard experience considering the current change in the climate. The annual amount of rainfall ranges between $1500 \mathrm{~mm}$ and $1800 \mathrm{~mm}$ with a mean relative humidity of about 70 percent. It has a fairly high and uniform temperature ranging between 20 degrees Celsius and 32 degrees Celsius with mean at 28 degrees Celsius. The district has five main soils, namely, Bekwai-Oda, Mim-Oda, Asikuma-AtewaAnsum/Oda, Kumasi-Asuansi/Nsuta-Offin, and Birim-Awaham/Chichi were compound associations and three geological formations. These formations are the Birimian, Tarkwaian, and granite rocks which are rich in mineral deposits. The district is drained by rivers such as the Fena, Oda, Ochi, and Offin. The current population of the district is estimated at 110,026 based on the 2010 population and housing census. About $80 \%$ of the people in the district are into agriculture and about $11 \%$ are in the services. Quite a sizeable number of the youth are also engaged in illegal mining (galamsey) activities, mostly along the banks or inside Fena River. Amansie Central District is one of the 27 administrative districts in the Ashanti Region [7]. Figure 1 presents the study area map.

All glassware and amber bottles for cadmium, copper, iron, lead, zinc, and mercury analysis were soaked in a detergent solution overnight after which they were washed and then rinsed with distilled water and soaked in $10 \%$ $\mathrm{HNO}_{3}$ solution overnight. They were then rinsed again with double distilled water and dried. For the mercury analysis, the glassware after being soaked in the $\mathrm{HNO}_{3}$ solution overnight was then rinsed with a $0.5 \% \mathrm{KMNO}_{4}$ solution. 


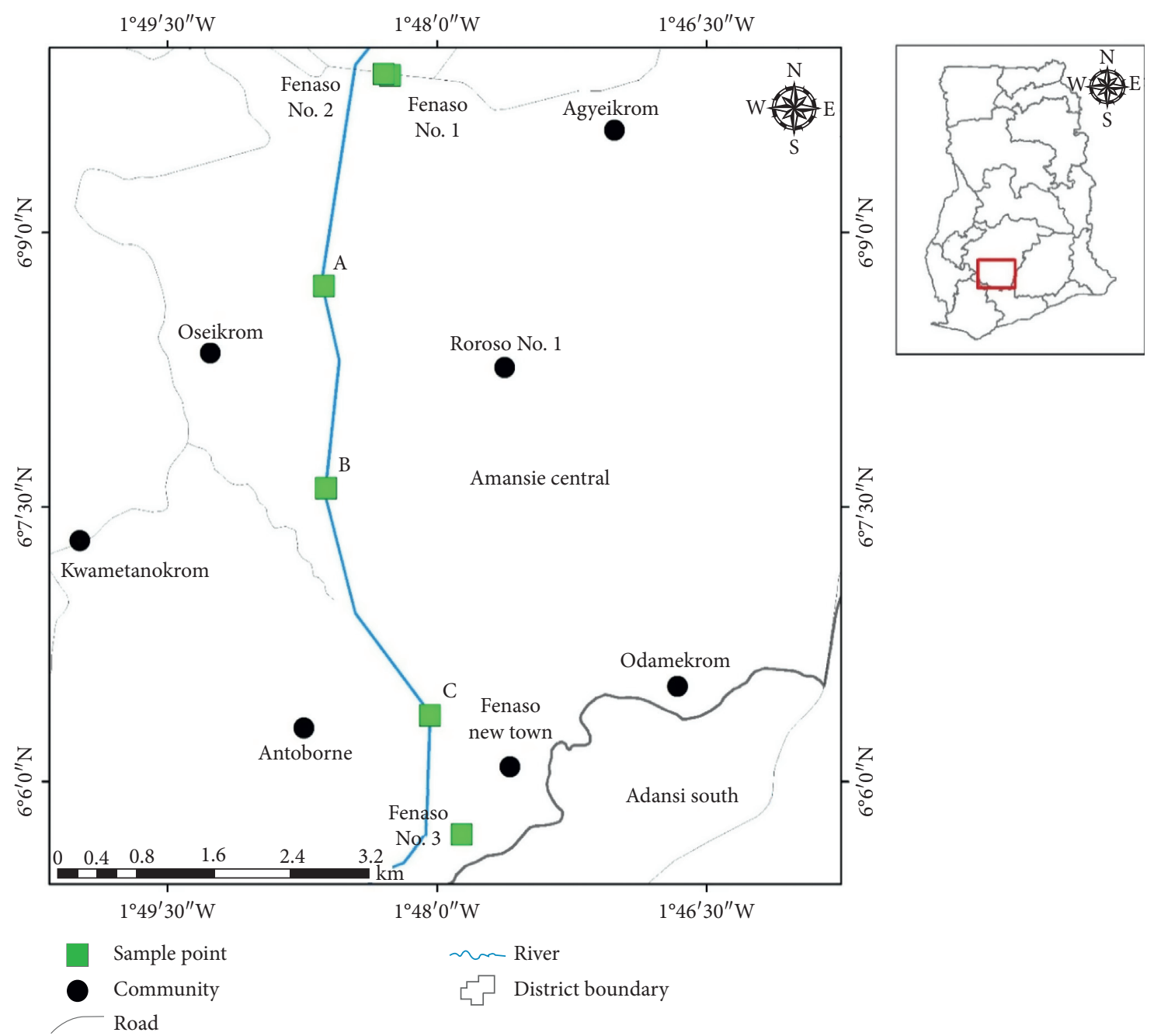

Figure 1: Map of the sampling points in Fena River in Amansie Central District.

They were finally rinsed first with tap water and then with distilled water and dried. From a total of 6 sampling points, 72 water samples were collected in laboratory, cleaned and rinsed 1.5-liter polyethylene bottles. Water samples were collected from January to December 2019. Samples were acidified with $0.24 \mathrm{M}$ nitric acid (analytical grade) and kept at $4^{\circ} \mathrm{C}$ in the dark before analysis.

Water samples were collected from the river at the following selected points: Fenaso number 1, Fenaso number 2 , sampling point " $A$," sampling point " $B$," sampling point " $C$," and Fenaso number 3. Sampling point " $A$ " was the only sampling area where there was virtually no illegal mining activity taking place. The sampling of water was done by dipping a $1.5 \mathrm{~L}$ plastic bottle below the water surface of the river at each of the designated sampling points. The sampling was in one-month intervals.

2.2. Water Quality Parameter. All the physicochemical parameters were measured in the field. The $\mathrm{pH}$ meter with model no. PHSB-320; BOQU was used to determine the temperature and hydrogen ion concentration $(\mathrm{pH})$ of the water samples. The pen-type conductivity meter and portable $2100 \mathrm{Q}$ turbidity meter were used to measure conductivity and turbidity, respectively.

2.3. Chemical and Sample Digestion. Analytical-grade reagents and deionized water were used in all the analyses. The water samples were acidified to $\mathrm{pH}<2$ after they were filtered using a $0.45 \mu \mathrm{m}$ cellulose membrane filter before being transported to the laboratory for analysis. $5 \mathrm{~mL} \mathrm{HNO}_{3}$ was added to a boiling tube containing $50 \mathrm{~mL}$ of the acid preserved sample. Using a graphite block digester, the sample was heated at $130^{\circ} \mathrm{C}$ until the volume reduced to about $25-20 \mathrm{~mL}$. Nitric acid was added to the sample whilst heating until the solution became light-colored or clear. The digested solution was cooled and made to the desired volume using deionized water and filtering through Whatman no. 41 filter paper.

2.4. Analytical Technique and Accuracy Check. The following heavy metals, namely, cadmium $(\mathrm{Cd})$, copper $(\mathrm{Cu})$, lead $(\mathrm{Pb})$, mercury $(\mathrm{Hg})$, zinc $(\mathrm{Zn})$, and iron $(\mathrm{Fe})$, were measured using dual atomizer and hydride generator atomic absorption spectrophotometer (model ASC-7000 no. A309654, 
Shimadzu, Japan). In order to avoid contamination and ensure accuracy, reagents of analytical grade from MES Equipment Ghana and ultrapure metal-free deionized water were used for all analyses. All glass and plastic wares were cleaned, and the instruments were precalibrated before measurement. All the results were expressed in mg/L. Matrix Spike recovery was in the range of $85 \%-100 \%$.

2.5. Assessment of Heavy Metals in Water. To establish the pollution contribution of the heavy metals, two indices, the Canadian Council of Ministers of the Environment (CCME) Water Quality Index (WQI) and Nemerow's Pollution Index (NPI), were applied. The detailed explanation of the indices is provided in the paragraphs that follow.

2.6. Water Quality Index (WQI). The CCME WQI uses the scope, frequency, and amplitude in assessing the quality of a water source. The scope measures the number of variables that fall outside the water quality standards, whereas the frequency measures the number of times a particular parameter falls outside the standard. The amplitude is the difference in concentration between the measured sample and its objective (standard). Mathematically, the three factors can be put together to assess the ambient water quality. However, it must be noted that there should be at least a minimum of four sampling times with at least four variables before one can obtain a representative result, but there is no limitation to the maximum number of samples to use for analysis. $F_{1}$ (scope) represents the "failed variables," that is the percentage of variables that do not meet their objectives at least once during the period under consideration relative to the total number of variables measured and is mathematically expressed as

$$
F 1=\frac{\text { number of failed variables }}{\text { total number of variables }} \times 100 \text {. }
$$

$F_{2}$ (frequency) is the percentage of individual tests that do not meet objectives ("failed tests"). It is mathematically expressed as

$$
F 2=\frac{\text { number of failed tests }}{\text { total number of tests }} \times 100 \text {. }
$$

$F_{3}$ (amplitude) is the difference in the concentration between the failed test and their objectives. Calculation of $F_{3}$ involves three steps. The first is to estimate the number of times the individual concentrations are greater than (or less than, when the objective is a minimum) the objectives (excursion). This is mathematically expressed as

$$
\text { excursion }=\frac{\text { failed test value }}{\text { objective }}-1 \text {. }
$$

For the cases in which the test value must not fall below the objectives, such as that of $\mathrm{pH}$, the excursion is calculated as

$$
\text { excursion }=\frac{\text { objective }}{\text { failed test value }}-1
$$

The ratio of the sum of excursions to the total test is referred to as the normalized test of excursion or nse:

$$
\text { nse }=\frac{\sum_{i=1}^{n} \text { excursion }}{\text { number of tests }} \text {. }
$$

By an asymptotic function that scales the normalized sum of the excursions from the objectives (nse), $F_{3}$ is then calculated to yield a range between 0 and 100:

$$
F 3=\frac{\text { nse }}{0.01 \text { nse }+0.01} \text {. }
$$

After calculating for the three $F$ s, CCME WQI can be calculated as

$$
\mathrm{CCME} \mathrm{WQI}=100-\frac{\sqrt{F 1^{2}+F 2^{2}+F 3^{2}}}{1.732} .
$$

The detailed explanation of the calculated WQI values is presented in Table 1 .

2.7. Nemerow's Pollution Index (NPI). NPI is an index that measures the extent of pollution caused by individual parameters. In this regard, the measured concentration of the parameter is compared to its standard value as indicated in equation (8). The calculated value from equation (8) represents the pollution caused by a particular parameter:

$$
\mathrm{NPI}=\frac{C_{i}}{L_{i}}
$$

where $C_{i}$ is the observed concentration of the $i$ th parameter; $L_{i}$ is the permissible limit of the $i$ th parameter. A calculated NPI of less than or equal to 1 indicates the absence of pollution, and any value above 1 indicates pollution. The higher or bigger the value, the more significant the pollution effect.

\section{Statistical Analysis}

Excel was used to calculate the mean and standard deviations of the heavy metal concentration in the water samples. It was also used to estimate the WQI and NPI.

\section{Results and Discussion}

4.1. Water Quality Parameters. The results of the mean values of the physicochemical parameters and the minimum and maximum values of the sampling areas are presented in Table 2. Maintaining water of good quality is very crucial for the proper functioning of the environment as well as improving and increasing access to a safe water supply to reduce the 4 billion of the world population who suffer from diarrhea every year due to unsafe water use [8]. Water for the environment to function properly is no longer an issue of debate; however, the debate rather has to do with how to maintain water of good quality to help sustain effective and efficient functioning of the environment. $\mathrm{pH}$ of water is a very important parameter with a strong influence on the survival of aquatic organisms. High or low $\mathrm{pH}$ can cause the death of aquatic organisms. $\mathrm{pH}$ also influences the solubility of certain toxic compounds such as heavy metals in a river [9]. 
TABLE 1: CCME water quality index.

\begin{tabular}{ccc}
\hline Rank & Category & Explanation \\
\hline 95-100 & Excellent & Water quality is protected with a virtual absence of threat or impairment; conditions are very close to natural or pristine \\
levels
\end{tabular}

TABLE 2: Water quality parameter of Fena River.

\begin{tabular}{|c|c|c|c|c|c|c|c|}
\hline \multirow{2}{*}{ Parameter } & \multicolumn{3}{|c|}{ Fen 1} & \multicolumn{3}{|c|}{ Fen 2} & \multirow{2}{*}{ WHO standarc } \\
\hline & Mean and std & $\operatorname{Max}$ & Min & Mean and std & $\operatorname{Max}$ & Min & \\
\hline $\mathrm{pH}$ & $6.17 \pm 0.27$ & 6.63 & 5.82 & $5.81 \pm 0.41$ & 6.33 & 5.21 & $6.5-9$ \\
\hline Temp. & $23.58 \pm 0.17$ & 23.85 & 23.31 & $23.45 \pm 0.17$ & 23.73 & 23.08 & $25-30^{\circ} \mathrm{C}$ \\
\hline Turb. & $182.25 \pm 20.49$ & 213 & 148 & $194.33 \pm 16.34$ & 231 & 169 & $75 \mathrm{NTU}$ \\
\hline TSS & $2415.67 \pm 440.1$ & 3314 & 2560 & $2971.67 \pm$ & 3354 & 2830 & $500 \mathrm{mg} / \mathrm{L}$ \\
\hline TDS & $3165.33 \pm 207.83$ & 3314 & 2560 & $3180.50 \pm 142.11$ & 3334 & 2730 & $500 \mathrm{mg} / \mathrm{L}$ \\
\hline Conductivity & $1236.75 \pm 59.38$ & 1311 & 1103 & $1268 \pm 19.44$ & 1300 & 1238 & $1000 \mathrm{mg} / \mathrm{L}$ \\
\hline $\mathrm{Pb}$ & $0.192 \pm 0.23$ & 0.81 & BDL & $0.72 \pm 0.29$ & 1.04 & 0.23 & $0.01 \mathrm{mg} / \mathrm{L}$ \\
\hline $\mathrm{Cd}$ & $0.14 \pm 0.19$ & 0.7 & $\mathrm{BDL}$ & $0.02 \pm 0.01$ & 0.04 & 0.01 & $0.003 \mathrm{mg} / \mathrm{L}$ \\
\hline $\mathrm{Cu}$ & $0.09 \pm 0.03$ & 0.14 & 0.03 & $0.09 \pm 0.06$ & 0.24 & 0.01 & $2 \mathrm{mg} / \mathrm{L}$ \\
\hline $\mathrm{Fe}$ & $12.94 \pm 1.57$ & 16.43 & 11.03 & $13.01 \pm 0.71$ & 14.09 & 11.63 & $2 \mathrm{mg} / \mathrm{L}$ \\
\hline \multirow[t]{2}{*}{$\mathrm{Zn}$} & $0.81 \pm 0.14$ & 0.91 & 0.46 & $0.84 \pm 0.09$ & 1.02 & 0.71 & $5 \mathrm{mg} / \mathrm{L}$ \\
\hline & \multicolumn{3}{|c|}{ Point $A$} & \multicolumn{3}{|c|}{ Point $B$} & \\
\hline $\mathrm{pH}$ & $6.38 \pm 0.19$ & 6.7 & 6.12 & $5.44 \pm 0.23$ & 5.88 & 5.11 & $6.5-9$ \\
\hline Temp. & $24.11 \pm 0.22$ & 24.5 & 23.87 & $23.67 \pm 0.08$ & 23.76 & 23.47 & $25-30^{\circ} \mathrm{C}$ \\
\hline Turb. & $133.08 \pm 19.93$ & 160 & 103 & $372.42 \pm 59.71$ & 445 & 262 & $75^{\circ} \mathrm{NTU}$ \\
\hline TSS & $116.42 \pm 9.36$ & 2125 & 1002 & $659.58 \pm 67.58$ & 3411 & 3011 & $500 \mathrm{mg} / \mathrm{L}$ \\
\hline TDS & $1511.67 \pm 382.42$ & 2132 & 985 & $3160.25 \pm 119.21$ & 3411 & 3011 & $500 \mathrm{mg} / \mathrm{L}$ \\
\hline Conductivity & $144.58 \pm 19.37$ & 184 & 122 & $252.5 \pm 23.57$ & 283 & 206 & $1000 \mathrm{mg} / \mathrm{L}$ \\
\hline $\mathrm{Pb}$ & BDL & $\mathrm{BDL}$ & BDL & $0.05 \pm 0.02$ & 0.10 & 0.02 & $0.01 \mathrm{mg} / \mathrm{L}$ \\
\hline $\mathrm{Cd}$ & $0.01 \pm 0.00$ & 0.01 & 0.01 & $0.07 \pm 0.07$ & 0.21 & 0.01 & $0.003 \mathrm{mg} / \mathrm{L}$ \\
\hline $\mathrm{Cu}$ & $0.04 \pm 0.04$ & 0.12 & 0.01 & $0.03 \pm 0.01$ & 0.05 & 0.01 & $2^{\circ} \mathrm{mg} / \mathrm{L}$ \\
\hline $\mathrm{Fe}$ & $4.81 \pm 0.25$ & 5.21 & 4.48 & $6.45 \pm 0.77$ & 7.34 & 5.03 & $2^{\circ} \mathrm{mg} / \mathrm{L}$ \\
\hline \multirow[t]{2}{*}{$\mathrm{Zn}$} & $0.62 \pm 0.07$ & 0.75 & 0.52 & $1.11 \pm 0.36$ & 1.76 & 0.56 & $5^{\circ} \mathrm{mg} / \mathrm{L}$ \\
\hline & \multicolumn{3}{|c|}{ Point $C$} & \multicolumn{3}{|c|}{ Fen 3} & \\
\hline $\mathrm{pH}$ & $5.30 \pm 0.17$ & 5.65 & 5.09 & $6.07 \pm 0.21$ & 6.43 & 5.76 & $6.5-9$ \\
\hline Temp. & $23.69 \pm 0.16$ & 23.94 & 23.38 & $23.61 \pm 0.19$ & 23.84 & 23.27 & $25-30^{\circ} \mathrm{C}$ \\
\hline Turb. & $162.33 \pm 19.11$ & 181 & 122 & $309.58 \pm 44.49$ & 364 & 180 & $75 \mathrm{NTU}$ \\
\hline TSS & $132 \pm 42.22$ & 3312 & 3006 & $1930.58 \pm 521.36$ & 2925 & 1022 & $500 \mathrm{mg} / \mathrm{L}$ \\
\hline TDS & $3130.25 \pm 79.52$ & 3312 & 3006 & $3284.08 \pm 234.02$ & 3701 & 3011 & $500 \mathrm{mg} / \mathrm{L}$ \\
\hline Conductivity & $196.5 \pm 9.76$ & 211 & 182 & $333.75 \pm 27.70$ & 373 & 297 & $1000 \mathrm{mg} / \mathrm{L}$ \\
\hline $\mathrm{Pb}$ & BDL & $\mathrm{BDL}$ & $\mathrm{BDL}$ & $0.11 \pm 0.02$ & 0.13 & 0.08 & $0.01 \mathrm{mg} / \mathrm{L}$ \\
\hline $\mathrm{Cd}$ & $0.12 \pm 0.03$ & 0.17 & 0.08 & $0.05 \pm 0.01$ & 0.06 & 0.04 & $0.003 \mathrm{mg} / \mathrm{L}$ \\
\hline $\mathrm{Cu}$ & BDL & 0.01 & BDL & $0.06 \pm 0.02$ & 0.11 & 0.04 & $2 \mathrm{mg} / \mathrm{L}$ \\
\hline $\mathrm{Fe}$ & $0.38 \pm 0.12$ & 0.57 & 0.17 & $11.3 \pm 0.41$ & 12.07 & 10.98 & $2 \mathrm{mg} / \mathrm{L}$ \\
\hline $\mathrm{Zn}$ & $0.86 \pm 0.11$ & 1.05 & 0.67 & $0.62 \pm 0.11$ & 0.82 & 0.46 & $5 \mathrm{mg} / \mathrm{L}$ \\
\hline
\end{tabular}

Fen 1=Fenaso number 1; Fen 2=Fenaso number 2; Fen 3=Fenaso number 3; TDS=total dissolved solids; TSS =total suspended solids; Temp. $=$ temperature; Turb. $=$ turbidity; and $\mathrm{BDL}=$ below detection limit $(0.001 \mathrm{ppm})$.

The majority of aquatic creatures prefer a $\mathrm{pH}$ range of 6.5-9.0, even though some can live outside that $\mathrm{pH}$ range [10]. The acidity of the surrounding environment can also affect $\mathrm{pH}$ of water. All the sites studied at one time recorded $\mathrm{pH}$ values below the World Health Organization (WHO) permissible limits (Table 2). Only two out of the six sites (point $A$ and Fen 1 ) studied recorded $\mathrm{pH}$ values within the
WHO permissible values during the sampling period ( $\mathrm{Ta}$ ble 2). The consistent low $\mathrm{pH}$ values recorded within the study area are displayed in the mean $\mathrm{pH}$ range 5.3-6.38 measured in all the sites which fell below the WHO permissible limits of 6.5-9. The measured $\mathrm{pH}$ range in the study area is not suitable for aquatic organisms [11]. Furthermore, low $\mathrm{pH}$ has the potential to dissolve heavy metals into water: 
this is a public health concern as some farmers still use water for irrigation and domestic purposes.

According to Carr and Neary [12], the temperature is very important in the aquatic environment because it speeds up the rate at which chemical reactions such as (a) photosynthesis occur, (b) how pollutants, parasites, and other pathogens interact with aquatic residents, and (c) influence of the solubility of dissolved oxygen in water. The minimum and maximum temperatures measured within the period of study were stable (Table 2); however, it was below the acceptable limit of $25-30^{\circ} \mathrm{C}$ [12]. The low and stable temperatures measured in the study area are not conducive for the growth and survival of living organisms in the study area: this may be a contributing factor to the extinction of some fishes in the area claimed by the fishermen. Besides the temperature, there might be other contributing factors to the gradual disappearance of fishes in the area.

Even though all streams carry some level of SSs [13], when the levels increase beyond the carrying capacity of the river, they alter the chemical, biological, and physical properties of the river [14]. The cause of a high level of suspended solids in rivers may be due to quarries or mines or discharge of washings from a sandpit $[9,15]$. According to Ireland [15], (1) the suspended solids may consist of algal growths: an indication of severe eutrophic conditions; (2) SSs reduce the light penetration in surface waters and interfere with the life of aquatic species such as fishes and plants. The SSs may have a high composition of organic matter that can aid their decomposition and depletion of oxygen in a river and result in fish kill [13]. Finally, SSs have the potential of settling on the river bed to create septic conditions and produce offensive conditions. The highest and lowest SSs were recorded in Fen 2 and point $A$, respectively (Table 2). This high concentration of SS in the study area is due to illegal mining occurring in and around the river since no major industry or irrigation agriculture is occurring in the area. The high level of SS has the potential to create septic conditions and result in fish kill or fishes migrating to other parts of the river for survival: an explanation to fishermen in the area experiencing low fish catch.

The minimum and maximum turbidity within the study area were in the range of 103 to 445 NTU. Point $A$ recorded the lowest mean value with point $B$ recording the highest value (Table 2). The low turbidity in point $A$ confirms the absence of the illegal mining activities in that site. Notwithstanding this, all the sites including point $A$ recorded turbidity above the permissible level (Table 2). The observed turbidity in site $A$ is usually transported from Fen 1 and Fen 2 since they are at the upstream and in the case of point $B$, it may be due to the upstream effect together with what is happening within that site. The high turbidity in the studied river has the potential to limit the dissolved oxygen in the river. Hence, as turbidity increases, aquatic organisms compete for the limited oxygen with available organics in water [16]. This can also contribute to fishes migrating to more comfortable areas or dying due to limited oxygen.

There are four categories into which total dissolved solids (TDS) in water could be classified. The type "I" that is TDS $<1,000 \mathrm{mg} / \mathrm{L}$ is for freshwater; type "II" is brackish water with TDS between 1,000 and $10,000 \mathrm{mg} / \mathrm{L}$; type "III" is saline water with TDS from 10,000 till $100,000 \mathrm{mg} / \mathrm{L}$; and type IV is brine water with TDS $>100,000 \mathrm{mg} / \mathrm{L}$ [17]. The sampling points Fen 3 and point " $A$ " recorded the highest and lowest value of TDS in the area; however, they were above the WHO standard (Table 2). Only the sampling point " $A$ " measured freshwater (type "I") TDS value. The remaining sites recorded brackish water TDS. The brackish water condition in the river could be part of the cause of the fishes migrating to where freshwater conditions pertain.

Electrical conductivity is the measure of the extent to which water conducts electricity and is directly proportional to the ionic content of water. A sharp change in the conductivity of a river is an indication of possible pollution [12]. Mostly, the electrical conductivity of freshwater is in the range of $10-1000 \mu \mathrm{S} / \mathrm{cm}$ [18]. The values of conductivity ranged from 182 to 1311 during the period of study (Table 2). All the sites recorded permissible conductivity except Fen 1 and Fen 2. The observed conductivity in Fen 1 and Fen 2 has the potential to create toxic conditions in the river and create unstable conditions for living organisms [12].

4.2. Metal Concentration in Water. The results obtained from the analysis of the heavy metals are shown in Table 2. The concentration of the different metals varied from site to site. The concentration of the metals $\mathrm{Cu}$ and $\mathrm{Zn}$ were below the WHO permissible limit within the study period in the study area. Mercury concentration in the entire study area within the study period is zero. The metal concentration $\left(\mathrm{mgL}^{-1}\right)$ in water was as follows: $\mathrm{Cd}>\mathrm{Pb}>\mathrm{Fe}>\mathrm{Zn}>\mathrm{Cu}>\mathrm{Hg}$. The highest mean concentration of $\mathrm{Pb}$ measured in the river was $0.72 \mathrm{mgL}^{-1}$. The minimum and maximum values of $\mathrm{Pb}$ measured within the study area are 0 and $1.04 \mathrm{mgL}^{-1}$, respectively. The minimum value was recorded in points " $A$ " and " $C$ ", whereas the maximum value was recorded in "Fen 2." The mean concentration of the $\mathrm{Pb}$ in Fen 1 and Fen 2 is relatively higher than all the sites due to the intensity of the mining in those sites (Table 2). The mean and the maximum values are all far above the WHO permissible levels for drinking water. The highest mean $\mathrm{Cd}$ concentration in the river was recorded in Fen 1 upstream (Table 2). The maximum and minimum values of $\mathrm{Cd}$ were all recorded in Fen 1 (Table 2). The mean Cd is far above the WHO standard (Table 2) and renders water unsafe for drinking. The highest and lowest mean concentration of $\mathrm{Fe}$ were recorded in Fen 2 and point $C$, respectively (Table 2). The high level of Fe recorded in Fen 2 may be associated with the increase in the illegal mining activities which took place in and around the river at the time. The $13 \mathrm{mgL}^{-1}$ concentration of the "Fe" is of concern as it has the potential to cause problems in water treatment plants.

4.3. Assessment of Pollution Potentials. The calculated Nemerow pollution index (NPI) and water quality index (WQI) of physicochemical parameters studied in the river are presented in Table 3. The NPI values ranged from 7.40 to 0.12 for the physical parameters and 270.33 to 0 for the heavy metals. The zero measured is an indication that not all the metals polluted the area under study $(\mathrm{NPI}<1)$. Of the metals 
TABLE 3: Nemerow's pollution index and water quality index.

\begin{tabular}{|c|c|c|c|c|c|c|c|c|c|c|c|}
\hline Month & $\mathrm{Pb}$ & $\mathrm{Cd}$ & $\mathrm{Fe}$ & $\mathrm{Cu}$ & $\mathrm{Zn}$ & $\mathrm{pH}$ & Temp. & Turb. & TSS & Cond. & TDS \\
\hline \multicolumn{12}{|c|}{ Nemerow's pollution index (NPI) for Fen 1} \\
\hline Jan. & 33.1 & 110.33 & 7.57 & 0.06 & 0.18 & 1.08 & 1.18 & 2.60 & 5.99 & 1.20 & 6.03 \\
\hline Feb. & 15.5 & 51.66 & 8.22 & 0.06 & 0.17 & 1.06 & 1.17 & 2.51 & 6.07 & 1.10 & 6.42 \\
\hline Mar. & 0 & 0 & 6.66 & 0.01 & 0.09 & 1.08 & 1.19 & 2.68 & 6.10 & 1.30 & 5.12 \\
\hline April & 12.3 & 41 & 6.76 & 0.03 & 0.16 & 0.98 & 1.19 & 2.84 & 5.85 & 1.21 & 6.63 \\
\hline May & 81.1 & 270.33 & 6.02 & 0.04 & 0.17 & 1.12 & 1.18 & 2.37 & 4.27 & 1.30 & 6.34 \\
\hline June & 34.1 & 113.66 & 6.50 & 0.04 & 0.17 & 1.06 & 1.19 & 2.80 & 4.08 & 1.31 & 6.42 \\
\hline July & 1.2 & 4 & 6.60 & 0.04 & 0.12 & 1.00 & 1.17 & 2.24 & 4.36 & 1.20 & 6.61 \\
\hline Aug. & 2.1 & 7 & 6.07 & 0.04 & 0.17 & 0.98 & 1.20 & 2.12 & 4.23 & 1.20 & 6.58 \\
\hline Sept. & 1.1 & 3.66 & 5.52 & 0.07 & 0.18 & 1.07 & 1.18 & 1.97 & 4.14 & 1.28 & 6.41 \\
\hline Oct. & 2.2 & 7.33 & 6.01 & 0.03 & 0.16 & 1.11 & 1.20 & 2.51 & 4.02 & 1.24 & 6.40 \\
\hline Nov. & 31.2 & 104.00 & 5.61 & 0.06 & 0.18 & 1.07 & 1.19 & 2.33 & 4.62 & 1.26 & 6.40 \\
\hline Dec. & 16.5 & 55 & 6.09 & 0.07 & 0.18 & 1.06 & 1.18 & 2.19 & 4.24 & 1.22 & 6.62 \\
\hline WQI & & & & & & $=23.70$ & & & & & \\
\hline \multicolumn{12}{|c|}{ Nemerow's pollution index (NPI) for Fen 2} \\
\hline Jan. & 87.60 & 5.33 & 7.05 & 0.01 & 0.18 & 1.03 & 1.19 & 2.68 & 5.85 & 1.25 & 6.03 \\
\hline Feb. & 103.30 & 10.33 & 5.82 & 0.06 & 0.20 & 1.20 & 1.18 & 2.81 & 6.10 & 1.30 & 6.42 \\
\hline Mar. & 102.10 & 4 & 6.04 & 0.07 & 0.20 & 1.06 & 1.21 & 3.08 & 6.10 & 1.28 & 5.66 \\
\hline April & 86.60 & 7.33 & 6.72 & 0.06 & 0.15 & 1.06 & 1.18 & 2.52 & 5.85 & 1.27 & 6.62 \\
\hline May & 56.10 & 3.67 & 6.57 & 0.04 & 0.16 & 1.20 & 1.19 & 2.76 & 5.87 & 1.25 & 6.24 \\
\hline June & 43.20 & 4 & 6.61 & 0.12 & 0.16 & 1.19 & 1.21 & 2.59 & 5.88 & 1.24 & 6.42 \\
\hline July & 81.20 & 7 & 6.71 & 0.06 & 0.16 & 1.25 & 1.19 & 2.51 & 5.90 & 1.26 & 6.36 \\
\hline Aug. & 51.10 & 10.67 & 6.52 & 0.03 & 0.16 & 1.05 & 1.20 & 2.49 & 6.07 & 1.29 & 6.42 \\
\hline Sept. & 32.10 & 7 & 6.58 & 0.01 & 0.14 & 1.03 & 1.19 & 2.25 & 5.89 & 1.27 & 6.62 \\
\hline Oct. & 23.10 & 4.33 & 6.63 & 0.02 & 0.17 & 1.19 & 1.19 & 2.56 & 5.86 & 1.25 & 6.71 \\
\hline Nov. & 93.20 & 10.67 & 6.05 & 0.03 & 0.18 & 1.10 & 1.19 & 2.45 & 6 & 1.27 & 6.41 \\
\hline Dec. & 104.10 & 13.67 & 6.77 & 0.04 & 0.16 & 1.15 & 1.19 & 2.39 & 5.95 & 1.28 & 6.42 \\
\hline WQI & & & & & & $=20.33$ & & & & & \\
\hline \multicolumn{12}{|c|}{ Nemerow's pollution index (NPI) for point $A$} \\
\hline Jan. & 5.2 & 3.33 & 2.24 & 0 & 0.11 & 0.97 & 1.17 & 1.89 & 0.24 & 0.14 & 4.25 \\
\hline Feb. & 4.1 & 3.33 & 2.45 & 0.01 & 0.1 & 1.04 & 1.14 & 2.13 & 0.21 & 0.14 & 3.68 \\
\hline Mar. & 10.3 & 3.33 & 2.4 & 0.01 & 0.11 & 1.03 & 1.17 & 1.37 & 0.23 & 0.12 & 3.04 \\
\hline April & 6.2 & 3.33 & 2.56 & 0.01 & 0.15 & 1.02 & 1.15 & 2.08 & 0.26 & 0.15 & 2.05 \\
\hline May & 5.1 & 3.33 & 2.39 & 0.01 & 0.13 & 1.04 & 1.15 & 1.95 & 0.25 & 0.17 & 2.00 \\
\hline June & 3.2 & 3.33 & 2.24 & 0.06 & 0.13 & 1.03 & 1.17 & 1.97 & 0.21 & 0.14 & 2.82 \\
\hline July & 3.1 & 3.33 & 2.28 & 0.02 & 0.11 & 0.99 & 1.17 & 1.91 & 0.23 & 0.16 & 3.43 \\
\hline Aug. & 2.1 & 3.33 & 2.61 & 0.02 & 0.11 & 1.00 & 1.17 & 1.41 & 0.21 & 0.18 & 4.20 \\
\hline Sept. & 2.2 & 3.67 & 2.44 & 0.01 & 0.15 & 0.97 & 1.15 & 1.40 & 0.25 & 0.13 & 3.74 \\
\hline Oct. & 3.6 & 3.33 & 2.56 & 0.01 & 0.13 & 1.04 & 1.17 & 1.79 & 0.22 & 0.15 & 2.59 \\
\hline Nov. & 5.6 & 3.67 & 2.37 & 0.02 & 0.13 & 1.06 & 1.17 & 1.63 & 0.25 & 0.12 & 2.65 \\
\hline Dec. & 4.2 & 4.33 & 2.31 & 0.06 & 0.13 & 1.05 & 1.17 & 1.76 & 0.22 & 0.13 & 2.41 \\
\hline WQI & & & & & & $=55.05$ & & & & & \\
\hline \multicolumn{12}{|c|}{ Nemerow's pollution index (NPI) for point B } \\
\hline Jan. & 5.2 & 10.67 & 3.41 & 0.01 & 0.21 & 1.2 & 1.18 & 5.13 & 1.2 & 0.21 & 6.02 \\
\hline Feb. & 4.1 & 67 & 3.17 & 0.01 & 0.25 & 1.17 & 1.18 & 3.49 & 1.46 & 0.23 & 6.50 \\
\hline Mar. & 10.3 & 34.33 & 3.61 & 0.01 & 0.2 & 1.24 & 1.19 & 5.73 & 1.17 & 0.23 & 6.82 \\
\hline April & 6.2 & 34 & 2.94 & 0.02 & 0.2 & 1.17 & 1.18 & 5.93 & 1.55 & 0.24 & 6.24 \\
\hline May & 5.1 & 68.33 & 3.06 & 0.02 & 0.21 & 1.22 & 1.18 & 5.77 & 1.4 & 0.27 & 6.22 \\
\hline June & 3.2 & 10.67 & 2.52 & 0.02 & 0.25 & 1.17 & 1.19 & 4.28 & 1.35 & 0.26 & 6.11 \\
\hline July & 3.1 & 10.33 & 2.58 & 0.01 & 0.35 & 1.24 & 1.18 & 5.77 & 1.25 & 0.25 & 6.02 \\
\hline Aug. & 2.1 & 7 & 3.43 & 0.01 & 0.35 & 1.19 & 1.18 & 5.49 & 1.09 & 0.28 & 6.33 \\
\hline Sept. & 2.2 & 4 & 3.36 & 0.01 & 0.16 & 1.13 & 1.18 & 4.60 & 1.25 & 0.27 & 6.6 \\
\hline Oct. & 3.6 & 12 & 3.44 & 0.02 & 0.18 & 1.11 & 1.18 & 4.85 & 1.31 & 0.28 & 6.44 \\
\hline Nov. & 5.6 & 18.67 & 3.53 & 0.02 & 0.19 & 1.25 & 1.18 & 4.43 & 1.33 & 0.24 & 6.22 \\
\hline Dec. & 4.2 & 14 & 3.67 & 0.03 & 0.11 & 1.27 & 1.18 & 4.09 & 1.47 & 0.25 & 6.31 \\
\hline WQI & & & & & & $=30.81$ & & & & & \\
\hline \multicolumn{12}{|c|}{ Nemerow's pollution index (NPI) for point C } \\
\hline Jan. & 0 & 40.33 & 0.08 & 0 & 0.21 & 1.22 & 1.18 & 2.4 & 0.35 & 0.21 & 6.22 \\
\hline Feb. & 0 & 43.33 & 0.27 & 0 & 0.20 & 1.22 & 1.19 & 2.16 & 0.19 & 0.18 & 6.1 \\
\hline
\end{tabular}


TABLE 3: Continued.

\begin{tabular}{|c|c|c|c|c|c|c|c|c|c|c|c|}
\hline Month & $\mathrm{Pb}$ & $\mathrm{Cd}$ & $\mathrm{Fe}$ & $\mathrm{Cu}$ & $\mathrm{Zn}$ & $\mathrm{pH}$ & Temp. & Turb. & TSS & Cond. & TDS \\
\hline Mar. & 0 & 30.67 & 0.27 & 0 & 0.18 & 1.27 & 1.17 & 2.27 & 0.24 & 0.20 & 6.32 \\
\hline April & 0 & 43.33 & 0.29 & 0 & 0.15 & 1.28 & 1.18 & 2.24 & 0.46 & 0.20 & 6.01 \\
\hline May & 0 & 47 & 0.18 & 0 & 0.15 & 1.26 & 1.2 & 2.41 & 0.37 & 0.19 & 6.42 \\
\hline June & 0 & 57 & 0.18 & 0.01 & 0.17 & 1.19 & 1.18 & 1.71 & 0.21 & 0.19 & 6.21 \\
\hline July & 0 & 36.67 & 0.21 & 0 & 0.16 & 1.27 & 1.18 & 1.63 & 0.20 & 0.21 & 6.3 \\
\hline Aug. & 0 & 31.67 & 0.15 & 0 & 0.13 & 1.17 & 1.18 & 2.4 & 0.29 & 0.21 & 6.24 \\
\hline Sept. & 0 & 26 & 0.17 & 0.01 & 0.16 & 1.15 & 1.18 & 2.27 & 0.22 & 0.20 & 6.13 \\
\hline Oct. & 0 & 25.33 & 0.18 & 0 & 0.19 & 1.24 & 1.18 & 2.19 & 0.21 & 0.18 & 6.33 \\
\hline Nov. & 0 & 40.33 & 0.12 & 0 & 0.17 & 1.22 & 1.17 & 2.24 & 0.20 & 0.19 & 6.2 \\
\hline Dec. & 0 & 44 & 0.17 & 0 & 0.19 & 1.23 & 1.18 & 2.07 & 0.23 & 0.19 & 6.62 \\
\hline WQI & & & & & & $=56.81$ & & & & & \\
\hline \multicolumn{12}{|c|}{ Nemerow's pollution index (NPI) for Fen 3} \\
\hline Jan. & 12.9 & 20.67 & 5.53 & 0.03 & 0.12 & 1.07 & 1.19 & 4.85 & 4.05 & 0.32 & 6.02 \\
\hline Feb. & 12.4 & 13.67 & 6.04 & 0.05 & 0.10 & 1.06 & 1.18 & 4.19 & 4.18 & 0.31 & 7.04 \\
\hline Mar & 13.1 & 14 & 5.56 & 0.03 & 0.09 & 1.12 & 1.18 & 2.40 & 5.85 & 0.32 & 6.23 \\
\hline April & 12.2 & 11.67 & 5.49 & 0.02 & 0.10 & 1.13 & 1.19 & 4.67 & 3.30 & 0.37 & 6.80 \\
\hline May & 10.2 & 18 & 5.50 & 0.03 & 0.15 & 1.05 & 1.20 & 4.20 & 4.02 & 0.34 & 7.40 \\
\hline June & 8.1 & 19.67 & 6.02 & 0.03 & 0.13 & 1.06 & 1.17 & 4.08 & 4.08 & 0.31 & 6.64 \\
\hline July & 8.8 & 15.33 & 5.51 & 0.04 & 0.11 & 1.07 & 1.18 & 4.19 & 4.26 & 0.37 & 6.41 \\
\hline Aug. & 8.2 & 20.67 & 5.87 & 0.03 & 0.12 & 1.05 & 1.17 & 4.35 & 4.82 & 0.32 & 6.60 \\
\hline Sept. & 12.1 & 21 & 5.62 & 0.03 & 0.16 & 1.01 & 1.18 & 4.15 & 4.26 & 0.30 & 6.24 \\
\hline Oct. & 12 & 18 & 5.53 & 0.03 & 0.12 & 1.03 & 1.19 & 4.20 & 2.30 & 0.35 & 7.23 \\
\hline Nov. & 11 & 21 & 5.53 & 0.03 & 0.12 & 1.11 & 1.18 & 4.13 & 3.16 & 0.37 & 6.02 \\
\hline Dec. & 12.1 & 14.33 & 5.58 & 0.03 & 0.15 & 1.10 & 1.20 & 4.13 & 2.04 & 0.31 & 6.18 \\
\hline WQI & & & & & & $=26.57$ & & & & & \\
\hline
\end{tabular}

All values in italic show absence of pollution. Jan. $=$ January; Feb. $=$ February; Mar. $=$ March; Aug. $=$ August; Sept. $=$ September; Oct. $=$ October; Nov. $=$ November; and Dec. $=$ December.

studied, $\mathrm{Hg}$, $\mathrm{Cu}$, and $\mathrm{Zn}$ did not show any pollution effects in the area under study during the study period. Cd was the only metal that polluted all the areas under study and recorded the highest pollution effect of 273.33 in Fen 1(Table 3). The metal $\mathrm{Pb}$ was present in all the sites except point $C$. The highest pollution effect of $\mathrm{Pb}(104)$ was recorded in Fen 2. The higher values of $\mathrm{Cd}$ and $\mathrm{Pb}$ recorded in Fen 1 are due to the high level of illegal mining occurring in and around that stretch of the river. The metal Fe although also contributed to the pollution of the river, its pollution effect was a little less than 10 times its permissible value unlike that of $\mathrm{Cd}$ and $\mathrm{Pb}$ where the values were as high as 270 and 104 times their permissible values. This situation is very alarming. The NPI gives a clear picture of the most polluting metal among the metals to help in the process of planning and developing any remediation action or measure to reduce their introduction into the river. The values of the WQI for all the sites fell within the poor-marginal category (Table 1). The sites Fen 1, 2, and 3, as well as point " $B$," all fell within the poor water quality category. This means that, within such areas, the water quality is almost always threatened or impaired, which means the conditions usually depart from natural or desirable levels (Tables 1 and 3). The marginal category recorded by sampling points, $A$ and $C$, even though in comparison to the four sites looks better is still not good for domestic use. The quality category of marginal implies that the water quality is frequently threatened or impaired; conditions often depart from natural or desirable levels. The results of WQI imply that water is generally not good for human consumption considering the potential threat it poses to public health. Water if has to be used for domestic activities must go through some form of treatment to improve its quality.

\section{Conclusion}

The results identified $\mathrm{Cd}>\mathrm{Pb}>\mathrm{Fe}$ as the mean polluting order of the individual metals in the study sites (Table 3). The concentrations of the polluting metals were far higher than the permissible limit which is an indication that Fena River is polluted by three of the studied metals. Cd is the only metal among the three polluting metals identified to have polluted all the six sites. Cd also showed the highest pollution index at Fen 1. Metal pollution concentrations at the sites have been influenced by the intensity of illegal mining going on or that went on earlier before or during the sampling period. The water quality index confirms that the quality of water is marginal for two sites and poor for the remaining four sites. The poor and marginal quality of the river poses a threat to the health of the riparian communities which still depend on water for domestic activities such as cooking and feeding on fishes harvested from the river. It is recommended that intensive education of the riparian communities be done to stop their continual dependence on the river for domestic use [19-27].

\section{Data Availability}

The primary data used to support the findings of this study are available from the corresponding author upon request. 


\section{Conflicts of Interest}

The author declares that there are no conflicts of interest regarding the publication of this paper.

\section{Acknowledgments}

The author would like to thank the technicians and staff of the Technology Village of the University of Cape Coast (UCC) for providing laboratory space, facilities, and assistance to support the study.

\section{References}

[1] P. Chuhan-Pole, A. Dabalen, A. Kotsadam, A. Sanoh, and A. Tolonen, The Local Socioeconomic Effects of Gold Mining: Evidence from Ghana, The World Bank, Washington, DC, USA, 2015.

[2] G. Hilson, "The environmental impact of small-scale gold mining in Ghana: identifying problems and possible solutions," The Geographical Journal, vol. 168, no. 1, pp. 57-72, 2002.

[3] B. N. A. Aryee, B. K. Ntibery, and E. Atorkui, "Trends in the small-scale mining of precious minerals in Ghana: a perspective on its environmental impact," Journal of Cleaner Production, vol. 11, no. 2, pp. 131-140, 2003.

[4] African Union, Africa Mining Vision, African Union, Addis Ababa, Ethiopia, 2009.

[5] M. Kuhndt, F. Tessema, and M. Herrndorf, "Global value chain governance for resource efficiency building sustainable consumption and production bridges across the global sustainability divides," Environmental Research, Engineering \& Management, vol. 45, no. 3, 2008.

[6] M. Jerven and M. E. Duncan, "Revising gdp estimates in subsaharan Africa: lessons from Ghana," African Statistical Journal, vol. 15, pp. 13-24, 2012.

[7] Water Resources Commission, Pra Basin IWRM Plan, Water Resources Commission, Accra, Ghana, 2012.

[8] T. Yashoda, T. B. Reddy, and C. V. Ramana, "Pre-and postmonsoon variation in physicochemical characteristics in groundwater quality of mindi industrial area, visakhapatnam, India," International Journal of Environmental Sciences, vol. 4, no. 5, pp. 746-753, 2014.

[9] A. E. Duncan, N. De Vries, and K. B. Nyarko, "Assessment of heavy metal pollution in the main pra river and its tributaries in the pra basin of Ghana," Environmental Nanotechnology, Monitoring \& Management, vol. 10, pp. 264-271, 2018.

[10] J. P. Baker, D. P. Bernard, S. W. Christensen et al., Biological Effects of Changes in Surface Water Acid-Base Chemistry (No. ORNL/M-1086), Oak Ridge National Laboratory, Oak Ridge, TN, USA, 1990.

[11] J. S. Alabaster and R. Lloyd, Water Quality Criteria for Freshwater Fish: European Inland Fisheries Advisory Commission Report (FAO), FAO, Rome, Italy, 1980.

[12] G. M. Carr and J. P. Neary, Water Quality for Ecosystem and Human Health, UNEP, Nairobi, Kenya, 2008.

[13] P. A. Ryan, "Environmental effects of sediment on New Zealand streams: a review," New Zealand Journal of Marine and Freshwater Research, vol. 25, no. 2, pp. 207-221, 1991.

[14] G. S. Bilotta and R. E. Brazier, "Understanding the influence of suspended solids on water quality and aquatic biota," Water Research, vol. 42, no. 12, pp. 2849-2861, 2008.
[15] E. P. A. Ireland, Parameters of Water Quality-Interpretation and Standards, Environmental Research Unit, Lansing, MI, USA, 2001.

[16] J. D. Allan, "Stream ecology: structure and function of running waters," Journal of the Marine Biological Association of the United Kingdom, vol. 30, pp. 233-263, 1995.

[17] D. K. Todd and L. W. Mays, Groundwater Hydrology, John Wiley \& Sons, Hoboken, New Jersey, USA, 2005.

[18] D. Chapman, Water Quality Assessment: A Guide to the Use of Biota, Sediments, and Water in Environmental Monitoring, Cambridge University Press, Cambridge, UK, 1992.

[19] S. M. Banchirigah, "Challenges with eradicating illegal mining in Ghana: a perspective from the grassroots," Resources Policy, vol. 33, no. 1, pp. 29-38, 2008.

[20] C. G. Cude, "Oregon water quality index a tool for evaluating water quality management effectiveness," Journal of the American Water Resources Association, vol. 37, no. 1, pp. 125-137, 2001.

[21] E. J. Dawson and M. G. Macklin, "Speciation of heavy metals on suspended sediment under high flow conditions in the river aire, West yorkshire, UK," Hydrological Processes, vol. 12, no. 9, pp. 1483-1494, 1998.

[22] R. K. Gangwar, J. Singh, A. P. Singh, and D. P. Singh, “Assessment of water quality index: a case study of river ramganga at bareilly UP India," International Journal of Scientific \& Engineering Research-IJSER, vol. 4, no. 9, pp. 2325-2329, 2013.

[23] P. M. Haygarth, G. S. Bilotta, R. Bol et al., "Processes affecting transfer of sediment and colloids, with associated phosphorus, from intensively farmed grasslands: an overview of key issues," Hydrological Processes, vol. 20, no. 20, pp. 4407-4413, 2006.

[24] A. I. Macleod, S. N. Majid, Z. H. Ahmed, and N. Y. Hama, "Application of water quality index (wqi) as a possible indicator for agriculture purpose and assessing the ability of the self-purification process by qalyasan stream in sulaimani city Iraqi kurdistan region (IKR)," International Journal of Plant, Animal and Environmental Sciences, vol. 5, no. 1, pp. 162-173, 2015.

[25] B. Kronvang, A. Laubel, S. E. Larsen, and N. Friberg, "Pesticides and heavy metals in danish streambed sediment," The Interactions Between Sediments and Water, vol. 494, no. 1-3, pp. 93-101, 2003.

[26] A. F. Rusydi, "Correlation between conductivity and total dissolved solids in various types of water: a review," in Proceedings of the IOP Conference Series: Earth and Environmental Science, IOP Publishing, Banda Aceh, Indonesia, September 2018.

[27] World Health Organisation and United Nations, Childrens Fund, WHO, Geneva, Switzerland, 2000. 